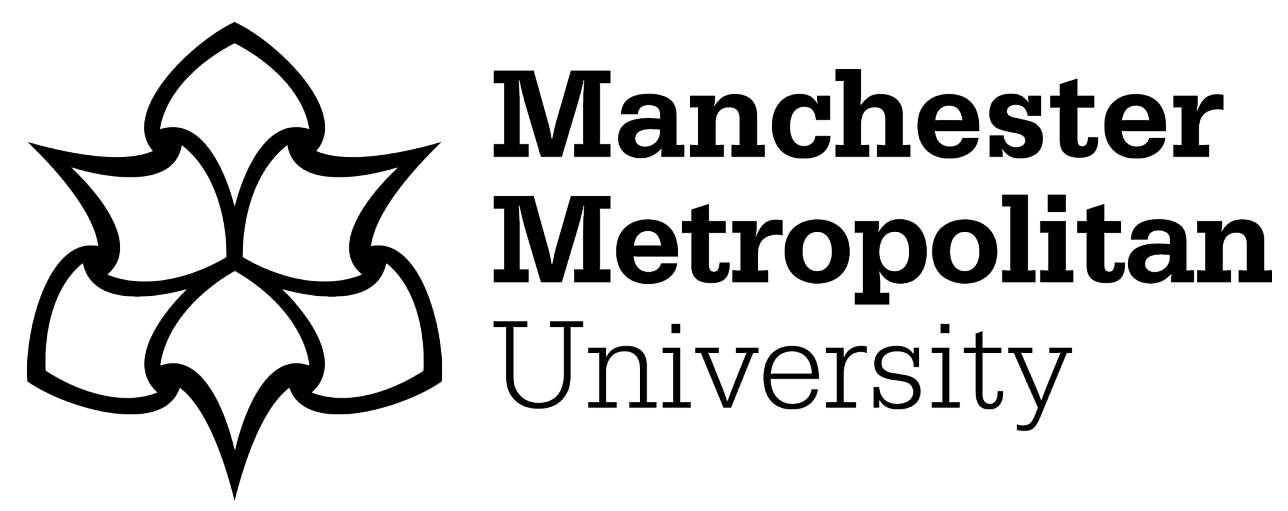

Hammersley-Fletcher, Linda ORCID logoORCID: https://orcid.org/00000002-4443-6856, Schostak, John and Darwish, Usama (2020) Leadership, the Vanishing Mediator and Organisation. In: Paradoxes of Democracy, Leadership and Education: Struggling for social justice in the twentyfirst century. Foundations and Futures of Education . Routledge. ISBN 9781138492967

Downloaded from: https://e-space.mmu.ac.uk/624793/

Version: Accepted Version

Publisher: Routledge

Please cite the published version 


\section{Chapter 10 Leadership, the Vanishing Mediator and Organisation}

Linda Hammersley-Fletcher, John Schostak, and Usama Darwish

It is common to argue that Western and Westernised societies are 'democratic'. However, it is difficult to describe the corporations that dominate their public and private sectors as exemplars of democratic organisation. In particular, their schools are largely driven by non-democratic managerialism imposed through a system wedded to hierarchy and inequality. In Rancière's (2005: 71) terms such so called 'democratic' states and their key organisations are ruled by a 'dominant intelligencia' who broadly, willingly or unwillingly, serve the interests of an economic elite. However, if a society claims to be democratic, then it would be reasonable to expect its key systems and institutions should exemplify forms of organisation and practice that articulate democratic principles. Thus, it is possible to argue as Dewey (1927) did, that reengaging in 'democratic practices' could reawaken the desire for freedoms that will allow all to have an equal voice in order to influence the present and the future of our children and thus of society, positively towards a more equal, socially just world. It is possible too as Robert Owen (1816) argued that by adopting co-operative rather than competitive practices society could be reformed for the better. The Rochdale pioneers drew upon the views of Owen and others to create a practical model that has grown to the extent that it has "supported at least half the world's population" (Woodin 2014: 2). It is relatively easy to point to such existing legacies and models of democratic forms of social, economic and indeed educational organisation that can be drawn upon (Fielding 2005; Fielding and Moss 2011) - but given contemporary societies are still overwhelmingly hierarchical and competitive, the odds remain stacked against their practical accomplishment. At its most radical, democracy demands both freedom and equality. Balibar (1994) called this the principle of égaliberté in order to articulate the co-extensiveness of freedom with equality. Thus for example, in a world of wealth inequality, where the billionaire can use wealth to influence political parties, manipulate markets and shape the behaviour of individuals in their market and political decision making, those who are relatively or absolutely poor have their freedom of choice of where to live, of access to the best education and the best jobs, restricted by the capacity of the rich. Geographically, the relation between inequality for the many and freedom for the few can be seen in the contrasts between thriving, well sourced centers of financial activity and depressed, overlooked areas that had once been 
industrial powerhouses and are now 'rust belts'. Infrastructures are skewed towards sustaining and responding to the demands of the rich and powerful. It echoes Simon's (1960) historical description of education for the 'two nations'. In this context, schools represent, if not a microcosm, then at least a quasi-laboratory for the testing of personal freedoms against the controls of superior forces. It is in this space where the place of authority constructs its powers over the subjective experience, behaviour and capacities to act of individuals. Here there is the individual in the role of adult of being in 'locus parentis' and teacher as the one who is supposed to know and be able to speak that knowledge to others. There is also the individual in the role of pupil, of being a locus of present and future potentials and of being a growing developing child in need of protection and in want of knowledge. This division contributes powerfully to the psychological conditions necessary to accept later divisions between bosses and employees and more generally between a governing class and those to be managed, disciplined, or moulded. The head teacher then is in a place of governance that amplifies and reinforces these divisions, a mediator, as it were, between the policy forming governing classes and those who most directly deliver policy face-to-face with the children whose performance is to be managed. It does not have to be this way though.

Lefort (1988) wrote of 'the place of power' to specify a structural position, as in Lacan's discourses of the master, that a monarch or tyrant occupies. The significance of the place of power is seen when a revolution de-thrones or unseats the monarch or tyrant. It leaves an 'empty place'. Of course, as in the popular television series Game of Thrones, contests can take place to occupy this structural position and once again fill it with a supreme tyrant. For Lefort, in democracy, the place of power must remain 'empty'. That is to say, no one person or group should fill the place of power with its forms of organisation, its laws and its access to infrastructures of coercive power as does a tyrant or ruling class. Rather, in democratic systems with democratic forms of organisation, no one voice is heard above another since in doing so the freedom of other voices to be heard and taken into account in all decision-making matters would be restricted. As described in chapter 2, the society of equals that this would produce, is barely on the horizon. There has been, as for example Lilla (2001) describes, a persistent counter attack by reactionaries opposed to the emancipatory, egalitarian, democratic processes set in train by Enlightenment thinkers, the political revolutions that followed in France, America and Haiti (then known as Saint Domingue). It is precisely this tension between democratisation and reactionary counter attacks that creates the place of contestation where the idea of the vanishing mediator, a term used by Jameson (1973), is situated. For our purposes, the head teacher and teacher have a choice between accepting the position of 'disciplining authority' prescribed by ruling policy makers or the position of being a democratic agent with the role of creating forms 
of organisation that invite others as equals. The reason they have this choice is that like any individual, they possess powers of thinking and imagination and can employ these with or against others to build forms of organisation that either exclude or include the voices of others. This means that the individual is first and foremost the possessor of powers - thinking, imagining, sensing, speaking, reaching out to others, forming projects with others - that can be deployed with or against others. The organisation of one's own powers in relation to the powers of others is creative of forms of social life. For those mainstream principals, head teachers and teachers who choose democratic approaches there is an immediate paradox to resolve. How can one be democratic in a hierarchical organisation?

This is precisely the problem faced by Shor (1996) for example as a democratising teacher who saw that it wasn't democrats who designed schools but authoritarian conservatives, jealously guarding against threats to their power, control, wealth and privilege. Shor writes of the prior views that students bring with them as they enter their schools and colleges. Those who aspire to join the elites sit towards the front, ready to respond to the teacher. Those whose views are negative seek to be as far from the teacher as possible, in the spaces Shor names as the 'Siberias' of the classroom, the self-isolating corners:

In an unequal, non-negotiated institution, students enact Siberia on the first day of class in the presence of a new teacher they have never met, without having heard me speak. Insofar as I am "the teacher," I am already part of their experience before they experience me. I already exist in their imaginations as part of their subordination to school authority, inside an education system that has been driving them to the rear. They know me before they meet me.

(Shor 1996:15)

It is impossible simply, he thinks, to say simply, now you are free, what do you want to do? Because:

Unlikely as it seems, I am trying to be a critical-democratic teacher in a setting where critical inquiry and power-sharing have virtually no profile in student experience. Faced by this democratic vacuum in everyday life, I have no choice but to use my institutional authority to ease into a process of shared power.

(Shor 1996)

This move implies a step towards what we see as the teacher as a vanishing mediator whose best course of action has so far been "to use my authority to organise a transformation of authority, 
step by step" (Shor 1996:20). This in turn implies that the teacher engages in creating antiauthoritarian practices and forms of organisation. So, the key issues for the chapter are how to move from an authoritarian context to a democratically open context, what mediates these, and how do you get from the one to the other? We attempt an answer to these issues by exploring the experience of engaging with a network of schools.

\section{Linda Working with Schools}

I have been working with a Teaching Schools Alliance for upwards of eight years, the Alliance comprising nine schools, one of which is a high school and the rest primary schools. The work involves me acting in the role of vanishing mediator to facilitate all levels of staff (including headteachers) with engagement in research approaches. This means that although I recognise expectations from others to lead in terms of research, I also seeks ways of dissolving the need for such leadership by encouraging each individual's capacity for research. Essentially this began by using research processes as a means to critically reflect on practice and engage with innovation in ways that are sustainable and able to be reproduced within the staff body as they gain confidence in asking awkward and difficult questions of each other and of themselves. In turn, leadership roles within the school also began to be interrogated.

Working alongside a school partner facilitator (Alice - a senior leader in the lead school within the Alliance in charge of professional development), we developed cross-school group research activity to engage with projects of the participating teachers' choosing, in order to increase their knowledge of undertaking critical analysis. The opening strategy was to use disruptive activities designed to be both fun and slightly uncomfortable at the same moment. For example, I have taken both groups of senior leaders and more general teaching groups on listening walks (adapted from a sound geography technique advocated by my colleague Michael Gallagher). These walks involve proceeding in single file, without speaking or writing and leading staff both around their own schools and also around their local environment. Clearly this activity causes some stress through disrupting usual behaviours and placing people in a somewhat embarrassing positions where they 'look silly' usually expressed in relieved laughter on returning to the training room. It also focusses them on listening and indeed seeing their environment differently. In this way my intention was to engage teachers on a research trajectory to help expose taken-for-granted practices, trouble teachers' minds about these practices, and raise questions about why teachers do what they do. It can be done in the context of Continuing Professional Development (CPD) where it is believed that: 
... the most significant form of CPD is something that makes you question what you thought was true (Fran-focus group response)

This challenge to the 'truth' of views is a significant and necessary step in the emergence of a critical public and more specifically the development of teachers as a body of critical professionals. Consequently, teachers were asked to repeat these activities with colleagues, and I challenged them to become comfortable with uncertainty and not knowing 'the answer'. We used academic literature to stimulate debate, exposed our own practises to each other, reflected upon our philosophies of learning and questioned all aspects of the environment, from the physicality of buildings to the political and policy arena within which schools are situated:

...there is so much focus in education today on exam results that it takes away from the quality of teaching, but it also means people can't see the wood for the trees... actually it's not until you really start to look and unpick and ask those questions that you realise how much are we assuming, but then we're making assumptions and other people are making assumptions and they're probably very different assumptions to ours which then generates more questions which can then move things on... (Jenny-focus group response)

The reflective practitioner is an old theme (Dreyfus 1981, Schon 1983) that reinforces, in particular, the development of the teacher as researcher (Stenhouse 1975) thereby laying the ground for various forms of action research (Lewin 1946, Elliott 1991), critical pedagogies (Freire 1972, Giroux 1989, Shor 1980) and indeed radical forms of research grounded in radical democracy (Schostak and Schostak 2008) that has the potential to create an effective public (Schostak and Schostak 2013, Schostak and Goodson 2020). As such, each school, each classroom becomes like a Deweyian (Mayhew and Edwards 1936) critical social laboratory for the underpinning of democracy. And in this project of forming the conditions for a critical public, each teacher counts.

A research student Usama Darwish interviewed the senior leader, my school partner Alice, as part of his doctoral study to ascertain what impact this work was having in creating such conditions. He has kindly allowed us to reference three relevant interviews. Alice (now the head teacher) told the story of our research development in the following way, 
What we were doing initially were discreet pieces of research, based on for example intervention programmes, what works and what does not work and that whole mindset. Research at the beginning was conducted and it was very much part of the appraisal targets to conduct a piece of research and so it went on as a discreet project in different classrooms conducted by different teachers and this is shared and disseminated and impacted on teachers' practices. And that is still happening, but there was a huge shift from a discreet piece of practice to research being integral to how our staff improve their own practice and I talk about, think about this eco-system and this symbiotic relationship between research and practice as they are not different, so they are not to be separated. Every single day the teacher is conducting research and we moved to that atmosphere within the school...

The move from discrete pieces of research to the building of an 'atmosphere', an 'eco-system' reinforces the move from individualistic to co-operative forms of organisation. In this shift, the role of the academic researcher moves from being an external intervention to becoming an internal request to be challenged as another senior leadership colleague Nanette explained:

We could hear through what Linda brings to the discussion, the rigour, the academic rigour that was needed to lift practice. So, following that we engaged more in using Linda's expertise to give a challenge to teachers, professional development wise, a challenge around practice using research... (Nanette - from Usama's interviews)

Rather than the initiative stemming from external sources, it became an internalised process where the researcher became a resource. Thus, as a first example, Alice asked a school improvement specialist to interview all staff and investigate their strengths and positioning in relation to school policy enactment. The specialist found some interesting variance between staff that demonstrated some very different positions being held amongst them. Alice then, after talking through her ideas with me, formed staff into groups that represented different stages of knowledge development and differing opinions. She then made it clear that all groups would be free from senior manager involvement and that they should work together to identify areas of concern or in need development in the school. They should then work together using literature and engaging in research to develop new policies which are then put in place without the Head 
needing to approve them. Thus, Alice was demonstrating trust and democratising the workplace. Hence, a small step towards the leader as 'vanishing mediator' had begun. Following a period of gathering to 'moan', teachers began to undertake research that was meaningful to them as practitioners and to the school which led to the formation policy:

It has moved from literally we are all going to get together and have a moan to there is something in this, we are going to try this, and have you seen what has been found somewhere else? ...staff are changing policy in the school as a result and this is not coming in any way shape or form from the senior leadership team, it is coming from research interest groups.... (Alice - from Usama's interview)

Given teachers questioning their own practices and the status of the 'truth' of their opinions and assumptions, to what extent then can the next step be to democratise the pupil-teacher relationship?

...children regularly come back with the fact that the teacher is the learner and the classroom belongs to them, and they do talk about 'I ask my teacher a question, they can't tell me the answer so we have to do our research', so they don't see that as a negative at all, they know that teachers are just like ... they know that the questions they are raising are something that they need to go away and think about it and do their research... (Alice - from Usama's interview)

These are perhaps small steps, like many other such small steps before them recorded in the radical education literature (Fielding and Moss 2010). However, each small step when shared through an alliance of schools, cumulates as indicated by Melissa a teacher participant in the Alliance research journey commenting to Usama about her experience:

When I first was involved in research it was about personal development and changing things in my classroom, so it was more sort of trying things and having the confidence, because I was relatively newly qualified when I started being involved in research... I developed confidence through it and the approach with which we develop everyday across the teaching school, so for example, I was involved in the last academic year ... I went to look at school priorities from across 
different schools in the Alliance, working at other schools ... and I was involved in [an academic conference presentation]. I think this gives people the confidence to change and also gives them a different way of looking at things...I think research makes you more reflective as a teacher, because you are constantly looking at different ways of doing things. You don't do it, just do it the way you have always done it because you have always done it.

The formation of an 'alliance' between schools is a critical step beyond the marginalised, innovative teacher (for example, Shor 1996), or indeed, the lone democratic school challenging the mainstream (for example Fielding 2005). Despite standing as powerful and influential examples, they do not necessarily create the infrastructure required to challenge and displace the mainstream system locked into delivering State policy.

In the Alliance the emergence of a horizontal infrastructure was enabled through the formation of cross-school groups having the purpose of reflecting upon and re-thinking practices. In this scenario teachers deemed specialist lead educators are paired with a research assistant from another school and then work with a teacher in a third school on a curriculum area of this last teacher's choosing. The two external participants go into the school with a desire to learn about practices, rather than as expert visitors, and the three staff work together on a research project to explore potentials and possibilities for new approaches to be introduced thereby operating in a democratic forum. Melissa had taken part in one of these Trio's and explained,

What happened is that they [the visiting staff] went in with the idea that they did not have the answers. We found that they really did not have the answers. That is where you need the open-minded teacher who understands research, some heads did struggle a little bit. They were paying the specialist to come in ... but the specialist did not have the answer and actually it was more powerful than the specialist going to free morning sessions and changing one thing, because of the teacher learning power to do the changes and how the teachers bought into it... They were doing it [researching an issue in practice] together rather than it being done to them. (Melissa-from Usama's interviews)

The 'Trio' is generative of small - almost homeopathic - challenges to taken for granted expectations that have been conditioned by mainstream hierarchical forms of organisation. This 
activity not only shifts practice in unexpected ways but also forms bonds between the schools within the Alliance and develops the knowledge and skills of those staff engaged in this work. That is to say, there is the progressive formation of countervailing infrastructures similar to what Rosanvallon (2012) somewhat confusingly calls counter-democratic practices. By this he means practices that are outside of mainstream policy and governmental structures of democratically elected governments and can thereby challenge and hold them to account. Similarly, the teachers of the Alliance are able to form relationships that, though sanctioned by their schools, are actually outside of the internal structures of discipline, control and authority of a given school. The legitimacy of the work of the Trio form of organisation as well as the researchbased work of the body of teachers across the schools of the Alliance is also celebrated and reinforced at an annual conference across the teaching school alliance where the work of staff is showcased and acts as a stimulus to re-orientate their thinking. This is further reinforced when staff present papers at academic conferences, and co-write articles as well as engage in higher educational qualifications as in the case of a senior member of staff who has begun doctoral work under my supervision. However, to create the conditions for a countervailing force, it is not enough simply to 'do research', as recognised by Nanette:

some schools say we do research. I say yeah ok, as if research is something that you can buy or get. It is a culture you create. (Nanettefrom Usama's interviews)

This sense of there being a particular kind of 'culture' that transcends the capitalist-like discourses of research as an 'off the shelf' consumer product has been critical in displacing the researcher as hired gun brought in to make and monitor change according to policy requirements.

As I have stated above, I wanted to place myself in the role of vanishing mediator. This has taken place in ways that were different to those I expected. Initially I presumed I would need to work alongside staff for two or three years after which point they would be self-sustaining. What I hadn't taken account of was the ways in which the development journey would shift and take on new directions. Initially there were some issues in facilitating staff to relinquish the notion that all projects had to be directly tied into school improvement and that they should have a tangible result (in terms of a statistically recognised improvement in results for example). Then teachers had to let go of the notion that the study should have an end result that proved they were 'right'. 
I don't like uncertainty, I like knowing what I should be doing because I

like to get it right. I hate not getting things right and I hate not completing things, and I hate failing. (Sam - focus group response)

The notion of no right or wrong answers took some time to become part of the culture. Indeed, they had to learn that apparent 'failure' teaches us a lot about education.

...in the first instance some of the people were quite reluctant coming in, they didn't really know what they were getting out of it and ... they've kind of become more, flexible in their approach ...understood more about where it's [research] going ... not that's it's got a goal but ... it's more open isn't it and its more ... of a contribution of ideas and that's important so it's more of a level playing field ... (Lou-focus group response)

I had to learn when it was appropriate to steer, when to let go, where to advise and where advice became a constraint. However, through very open and frank discussions we all learned together. I was not the expert telling them how it was to be done, I was a colleague with different expertise to them but who also needed to learn from them. This recalls Rancière's exploration of the 'ignorant school master'. By this he meant that we are all ignorant in some way and that a given role does not necessarily assure the holder has expertise or mastery. Rather, there needs to be the recognition of the intelligence of the other as necessary to building a mutually beneficial process of learning. Thus, we were on the journey together. However, as I stepped back from one set of activities, new activities began to rise from previous work. Hence my engagement with the group fluctuates according to what I can offer and what they need at any given point. The partner facilitator has described this as a continually vanishing mediator.

I work with groups to enhance practices in one area, gradually withdraw from this and let staff generate their own expertise, re-emerging to support another area of development. Nonetheless, my activity with the schools becomes less as they grow in strength. The difficulty of being a vanishing mediator is in the letting go! The senior leader Alice, working in partnership with me, has now taken on the headship of her school. I asked her to add her thoughts on my role and questioned whether in her eyes this made me a vanishing mediator.

I would say you have all the way through you have been a vanishing mediator, so you come in, you brought that challenge, you've, you know enabled us to think about ways forward and things to explore and then 
you know you have taken a step back from there and allowed that to happen.. I think though let's look at the wider relationship. I think what we do then is refocus on the next thing that emerges, so I think the work that we have done together has been a series where you have been the vanishing mediator and you have been able to withdraw from the situation and leave us to it to find our ways through it.. and we brought you back in as and when we felt we wanted that further support and challenge!... I do not feel that we have ever been done to or steered in a particular direction that wouldn't be right for our staff and children ... I think we have always felt that it has been a more supportive relationship... I think this has given me more knowledge of where we were heading as a school and being able to allow us as a school to explore that, we wouldn't have gone down that route otherwise, but you walked in and made that shift. You have given us the nudge, yes and keep nudging...

Alice went on to comment, ... [when we met] we were not aligned in our thinking because at that time we were in school, on a journey, a journey driven by the government, by Ofsted, and then all of a sudden, this person comes in flinging questions and challenges us that actually made us question what you know we are supposed to be doing in our school...

Now as headteacher, Alice faces the ever-present danger of simply taking her turn as the new leader in the process. As Lacan in his four discourses of the master (see chapter 1) has attempted to demonstrate, the old leader is made to give way to a new leader who is simply more accommodating. Hence Zizek's (2013) hope for the Thatcher of the left to provide a more congenial replacement to the dominant neoliberal and neoconservative mainstream that Thatcher, along with Reagan, promoted from the 1980s.

It is important then, to see that Alice too has handed over responsibilities to other staff and taken up new areas of development and, in the example given above, is facilitating all staff to engage with policy decision-making. She too, misses her former role but celebrates seeing others step forward and initiate their own developmental directions. As Nanette pointed out however, the research culture continues, 
...we believe in teachers reading and reading wisely, and quality

literature and that raises questions about their own practice and seeks to challenge the norms and beliefs, that we have been able to develop here by doing what we do, so yeah research continues to be a really integral part, a thread, a golden thread through everything that we do really. (Nanette - from Usama's interviews)

\section{Creating Change for a Debate Based Culture}

Reflecting methodologically, change began to take place at different phases of the involvement. Initially, the stance adopted in the research was of the kind more normally associated with ethnography. That is to say, it was a phase of building relationships of trust, being with participants in the context of their everyday working activities, observing, reflecting and getting to know the different discourses at play across the different spaces, places and contexts offered by each school in the network. In this ethnographic-like process of getting to know the network members through strategies of participation, a mapping of their different views was enabled through meetings and interviews. As people reflected and debated issues arose and thus cases for investigation emerged. Through the independent research role, a range of views could be identified and in staff discussion these could be placed into debate with each other. As Nanette explained,

It definitely lifted the quality and the nature of the debate we have as staff and it enabled us to question the policy to a degree and question the sort of things that are coming to us as school. And really question whether this is the right thing or the wrong thing and really question what about our own beliefs and more than anything create the culture of collaboration across the schools where you don't feel that you are working in silence. (Nanette - from Usama's interviews)

In that way each interview and conversation became a site of inter-views (Schostak 2006) where what was common or different between expressed views could be identified and the implicit arguments of views assessed in relation to implicit or explicit values as well as in relation to evidence. Important in this process is that no view is marginalised but is equally set into debates that draw upon research-based evidence to sustain or critique arguments. From this, courses of action could be identified in relation to implementing values agreed by debate, or in addressing issues that were considered to be important by the members of staff. As a result, the researcher's engagement was changing as the processes changed. With the agreed move 
towards more democratic participation, it was important for school members to engage in research processes to build cases for debate. It was then important for them to engage in research-based change processes, that is, a form of 'action research' emerged as a logical step to take. The academic research role thus increasingly acted as a 'vanishing mediator' at each stage in the development of school members. The academic researcher stepped back as school members increased in confidence with each other as well as with understanding the value of research practices to guide professional action. Undertaking action then necessitated exploring the consequences of decisions and actions. Those consequences became then the data for democratic forms of evaluation. That is to say, the evaluation was constructed deliberately to bring all views into debate equally. Although one particular view may be held by the most people, it did not necessarily mean that such popularity amounted to validity. It could well be that minority views accorded better with the evidence. Hence, all views had to be given equal weight in debate so that they could be fully assessed according to values, logical consistency and evidence. Thus, by mapping the range of views and valuing them under conditions of equality, it can be argued that the inter-view is a key move towards developing an agonistic democratic public in Mouffe's (2005) sense.

This agonism can turn two ways: to a split where the dominant side wins; or to a realignment where the disagreement at the heart of agonism is not squeezed out but remains as a creative element for the articulation of new forms of organisation, discourse, action and cultural expression. As Rancière (1999) puts it, the latter strategy amounts to being faithful to the disagreement. In contexts where people keep quiet, or show their discontent quietly, subtly the democratic task is to recover the disagreement. The 'symptoms' of disagreement vary but provide clues as to a missing voice in a debate. For a Multi-Academy Trust group I work with, a significant clue was the way that they valued 'quirkiness':

We always say we love quirky staff, you know we want people to be different and then we got a teacher called [Ollie] and he's very quirky and he's very different to what we're used to, and he started to sketch these post-it notes right quietly in his room and he started to give them to another teacher. It seems like a ... it was all based around this vulture and this vulture was like posing questions about life and death. [Ollie] is like very deep and very reflective and he like loves mythology and then one of the post-its said but what is the [school name] way? And SLT, and I found all these post-it notes and like you know sort of said to SLT guys come and have a read of these, and I was really interested to see like how we reacted as a team to this, because he was challenging. Like when ... he was challenging 
through that. Someone got really upset that they were messy, like the post-it notes were stuck all over the desk. Someone else was like what does he mean what is the [school] way? You know we're really clear about what the [school] way is and there was a bit of you know getting cross, but then I really, I think about him all the time now. When we're doing things, I think how would [Ollie] feel about this? And now that ... he's an NQT and what I've done with those post-its is I said to him I found your post ... I saw your post-it notes. He's so artistic, like you're really, really artistic. What are you going to do with them? And he was like well I don't know. Like they'll just end up stuffed in a cupboard somewhere, but I've recently put them all into a frame as like a comic strip. Him and I did it together. I Yes.

$R \quad$ We're going to put them up into the toilets, because that's how you celebrate him being quirky, and I don't want him to lose that, because on the middle leader training, even though he's only an NQT, wow, the stuff he's coming up with. He's the one who really made us confront this hierarchy of subjects over English and Maths, and then I'm like furiously texting [Kim], the assistant head who is leading the middle leaders, going oh my God [Kim] on the school report we put English and Maths first and we're saying that that's not our value, but look it's here, and then you know something else will pop into my brain and I'll be like look it's there, so I'm going to check back in with [Ollie] and just say to him I'm really interested in that.

The story is not finished - never will be perhaps - but that is not the point. Gradually, with each voice called into debate people are able to design organisations that support rather than suppress their views and their hopes.

\section{So What Have We Learned?}

Subjectivity is a place where power is continually contested directly in terms of 'speaking'. Whether speaking out or holding one's tongue, or paying lip service. It is the place from where the voice is heard loud and clear or where it stammers between one view or another. A key message then is how time, space (in terms of facilitating staff opportunities) and perhaps courage is needed (particularly on the part of school leaders) in essential to facilitate this approach to staff development. It is not a quick fix or without pain. It requires all involved to 
open up to being challenged and having to think through why they think, say or do what they do. But this seems essential in resisting Tourish's (2013) dark side of leadership. Holding attitudes, concepts and practices too closely denies the possibility of different and potentially exciting new ways to practice and develop the learning of others. There is also an important point around the need for someone to act as a stimulus, in this case, as Shor (1996) discussed, Linda employed institutional power to ease these staff into a process with implications for us all. That involved building trust and respect within and between educators. Through not making value judgements about things said but instead turning points into discussions, acknowledged the complexity of practice and the challenges faced in making beneficial decisions within notions that there is no absolute, that practice involves ongoing debates. Moreover, debate entered into in this way energised staff and gave them the powers needed to make decisions and take a different level of responsibility for their work. We worked at developing what Alice described as an 'ecosystem' with a 'symbiotic relationship' between research and practice.

Consequently when considering movements, such as that of the co-operative movement, who are taking on groups of schools with the intension of providing a new and explorative form of education, the illustrations of practice above signify that it is indeed possible to begin the task of democratising schooling where both staff and pupils are engaged in reflective challenge to the 'taken for granted'. A critical public discourse of agency is dependent upon our ability to hold up a mirror to see ourselves as others do and to imagine alternative ways of being. This means working together to resist teachers need to get things right and to simply do the things asked of them, drawing on strength of numbers, evidence and reading to think about how to change practice, whilst acknowledging the paradox within which schools are situated where rules-based criteria and measures of education appear often to have crushed educators' confidence and selfbelief. 